\title{
Setting agricultural science strategy in tumultuous economic times
}

Julian M. Alston, Agricultural Economist, UC Davis

Philip G. Pardey, Applied Economist, University of Minnesota Jennifer S. James, Agricultural Economist, Cal Poly, San Luis Obispo

$\mathrm{T}$ he international competitiveness and prosperity of U.S. agriculture depends on steady and rapid productivity growth fueled by public agricultural research and development (R\&D). Agricultural science benefits consumers and the environment, not just farmers. Enhanced productivity as a result of agricultural $R \& D$ means that consumers have access to a more abundant, cheaper, safer, higher quality, and more diverse and convenient food supply, produced with less stress on natural resources and the environment. From a global perspective, productivity growth allows agricultural production to increase faster than demand; food has become much cheaper over time in spite of a rapidly growing world population with rising per capita incomes. In the future, continuing productivity growth will be necessary to meet the challenges of ever-increasing demand for food along with mounting pressures on the natural resource base, exacerbated by new demands for biofuels crops.

Long-term and sustained growth in productivity is mainly the result of technological innovations adopted by farmers. Some develop through tinkering and trial and error on farms, but the greater share of agricultural innovations can be traced to organized, scientific and industrial R\&D efforts funded by government and the private sector.

Public investments in agricultural science have paid handsome dividends for society. Our formal analysis suggests that state-specific, benefit-cost ratios exceed 10 to 1, and are in many cases more than 20 to 1, for public agricultural research investments in the United States: \$1 of research investment today will generate a stream of future benefits equivalent to an immediate dividend of $\$ 20$ or more. These high benefit-cost ratios suggest that, as a state and nation, we have substantially underinvested in agricultural research, failing to capitalize on technological opportunities and foregoing potential large-scale, long-term net gains. Moreover, recent trends indicate that the extent of underinvestmentin productivity-enhancing agricultural science may be worsening.

In 2006, public and private spending on agricultural R\&D in the United States totaled $\$ 7.6$ billion (2000 prices). For many decades, up to the 1970s, such spending grew rapidly. Since then growth has slowed and become quite erratic. In addition, public-sector research has drifted away from on-farm productivity enhancements toward investments emphasizing food safety and quality, human health and nutrition, and natural resources and the environment. Much of this research could have social payoffs comparable to those from farm productivity-enhancing research; but a slower rate of growth in total spending and the drift of research emphasis will result in slower rates of farm productivity growth and a decline in global competitiveness of U.S. agriculture.

Early warning signs of these trends are already apparent, but the full consequences of shifts of research support will not be immediately obvious. Successful agricultural research

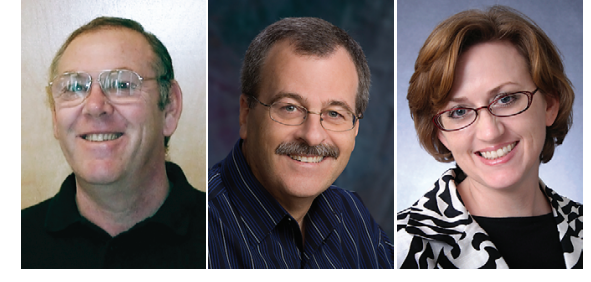

Alston, Pardey and James takes a long time to affect productivity. According to our analyses, it typically will take 10 to 20 years before the effects of a change in research spending implemented today will have their largest impacts, which may then continue for decades.

In California, aggregate agricultural production increased by more than $350 \%$ over the past 50 years even though the aggregate quantity of inputs increased by less than $70 \%$, reflecting increases in purchased inputs and capital partly offset by substantial labor savings. This productivity growth fueled by R\&D has been enormously valuable, saving resources worth more than $\$ 20$ billion per year in recent years that would have been required otherwise to produce the increased output.

However, since 1990, the rate of agricultural productivity growth has slowed significantly in developed countries, including the United States and California. From 1949 to 1989, productivity in California agriculture grew by about $2.2 \%$ per year (slightly above the national average rate of about 2.1\% per year). However, the growth rate slowed to $1.2 \%$ per year from 1990 to 2002 in California (slightly greater than the U.S. average of $1.1 \%$ per year). This measured slowdown is statistically significant, appreciable and economically important. A $1 \%$ compounding growth rate would result in productivity being 22\% higher after 20 years; $2 \%$ compounding growth would result in productivity being $49 \%$ higher after 20 years. Applied to a U.S. industry with an economic value in the range of $\$ 300$ billion per year, the difference between $1 \%$ and $2 \%$ compounding over time represents tens of billions of dollars per year even after only a decade or two.

California agriculture is large, diverse and different from that in other states and requires different kinds of research. California cannot rely entirely on others - whether in the private sector, federal government or overseas - to invest the amounts of money in the ways required to sustain an internationally competitive, environmentally sound and prosperous agricultural sector. The recent innovations in federal support for agricultural R\&D, in particular an increased emphasis on competitive grant programs and the provision of new funds for specialty crops research (see page 6) may work to California's advantage, but may only have a minimal impact on the fundamental problem of systematic underinvestment. The current state budget problems, and recent cuts in support for the agricultural experiment station, will further undermine California's long-run prospects of sustaining an internationally competitive agricultural sector. Reinvigorated investment by the state government and the private sector, potentially in new funding partnerships, will be required if we are to reverse these disturbing trends.

(At press time, the research discussed was in preparation for publication References will be posted at the California Agriculture Web site.) 